\title{
Broadband Light Source and Its Application to Near-Infrared Spectroscopy
}

\author{
Jun Ono ${ }^{1,2}$, Tatsuro Endo ${ }^{3}$, Kazuya Ohta ${ }^{1,4}$, Hirotaka Ono ${ }^{5}$, Yukina Maeda ${ }^{1}$, \\ Kousuke Senda ${ }^{1}$, Osanori Koyama ${ }^{1}$ and Makoto Yamada ${ }^{1, *}$ \\ 'Department of Electrical \& Information Systems, Osaka Prefecture University, \\ 1-1 Gakuen-cho, Nakaku, Sakai, Osaka 599-8531, Japan \\ ${ }^{2}$ Anritsu Devices Co., Ltd., 8-5 Tamura-cho, Atsugi, Kanagawa 243-0016, Japan \\ ${ }^{3}$ Department of Applied Chemistry, Osaka Prefecture University, \\ 1-1 Gakuen-cho, Nakaku, Sakai, Osaka 599-8531, Japan \\ ${ }^{4}$ Trimatiz Limited, 801 La Pacifique B, 4-7-12 Minamiyawata, Ichikawa, Chiba 272-0023, Japan \\ ${ }^{5}$ NTT Device Technology Laboratories, NTT Corporation, \\ 3-1 Morinosato-Wakamiya, Atsugi, Kanagawa 243-0198, Japan
}

(Received January 20, 2015; accepted March 11, 2015)

Key words: $1.8 \mu \mathrm{m}$ broadband light source, near-infrared spectroscopy, organic solute concentration, alcohol concentration

A new $1.8 \mu \mathrm{m}$ broadband light source for measuring concentrations of organic solutes is developed by combining an amplified sponteneous emission (ASE) light source that uses a $\mathrm{Tm}^{3+}-\mathrm{Tb}^{3+}$-doped fiber and commercially available light sources. The ASE intensity exceeded $-50 \mathrm{dBm} / \mathrm{nm}$ for a bandwidth of $\sim 1520$ to $\sim 1850 \mathrm{~nm}$. We constructed a near-IR spectroscopy system with the developed broadband light source and confirmed its effectiveness for evaluating concentrations of organic solutes. The system can measure several organic solutes at low volumetric concentrations of around $0.3 \%$. Furthermore, we used the system to evaluate the alcohol concentration of sake. We found that we could accurately determine an ethanol concentration within $1.5 \%$ of the accepted value in sake.

\section{Introduction}

Infrared (IR) light sources operating at around $1.8 \mu \mathrm{m}$ have been developed ${ }^{(1-10)}$ for applications in a wide variety of fields including medical surgery, industrial machining,

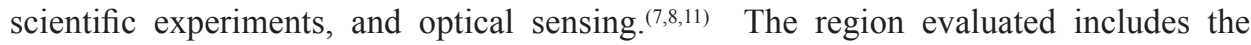
window wavelength of water and many other absorption peaks based on molecular vibrations such as $\mathrm{C}-\mathrm{H}, \mathrm{C}-\mathrm{H}_{2}$, and $\mathrm{S}-\mathrm{H} .{ }^{(12)}$ Moreover, these sources may be used for future optical transmission systems beyond $1.6 \mu \mathrm{m}$ as well as in the development of their components if we employ a hollow core photonic bandgap fiber to overcome the capacity limit of conventional systems. ${ }^{(13,14)}$

\footnotetext{
"Corresponding author: e-mail: myamada@eis.osakafu-u.ac.jp
} 
Three candidates for achieving a broadband light source in the $1.8 \mu \mathrm{m}$ band are a supercontinuum (SC) light source, ${ }^{(6)}$ a superluminescent diode (SLD), and an amplified spontaneous emission (ASE) light source. ${ }^{(9)}$ Although an SC light source can supply a broadband spectrum with high output power, it is very expensive, and the spectrum has poor stability because the nonlinear behavior of an optical fiber is used to generate the spectrum. An SLD, which is both small and inexpensive, can generate a broadband spectrum. However, increased ripple in the spectrum must be prevented when the output is increased, and there is no commercially available device that operates in the $1.8 \mu \mathrm{m}$ band. The ASE can be fabricated at a relatively low cost and generate a broadband spectrum with a high output power and no ripple.

We have successfully developed the first $1.8 \mu \mathrm{m}$ band ASE light source using a $\mathrm{Tm}^{3+}-\mathrm{Tb}^{3+}$-doped fiber as an active medium. ${ }^{(9)}$ We have also confirmed that the source is effective for constructing a near-IR spectroscopy system, which allows us to measure low concentrations of organic solvents in water. ${ }^{(15)}$

In this paper, we report a broadband light source for measuring concentrations of organic solutes that we constructed with a $1.8 \mu \mathrm{m}$ band ASE light source and its applications to near-IR spectroscopy. In $\S 2$, we describe the configuration and basic characteristics of the $1.8 \mu \mathrm{m}$ band ASE light source in detail. Moreover, we report the output spectrum of a broadband light source that we constructed for organic solute measurement using a $1.8 \mu \mathrm{m}$ band ASE light source and commercially available light sources such as a $1.65 \mu \mathrm{m}$ band SLD light source and a $1.55 \mu \mathrm{m}$ band ASE light source in parallel. Section 3 describes the setup of the near IR spectroscopy system and provides results for the measurement of organic solutes such as ethanol, methanol, and dimethyl sulfoxide. Furthermore, we report the evaluation of alcohol concentration in sake, which is an example of an industrial application of our broadband light source.

\section{Broadband Light Source with $1.8 \mu \mathrm{m}$ Band ASE Light Source}

\section{1 $1.8 \mu \mathrm{m}$ band ASE light source}

Figure 1 shows the configuration of the $1.8 \mu \mathrm{m}$ band ASE light source we fabricated. The light source consists of an ASE light generation unit and an emission characteristic improvement unit. We used a 1.2/1.8 $\mu \mathrm{m}$ band wavelength division multiplexer

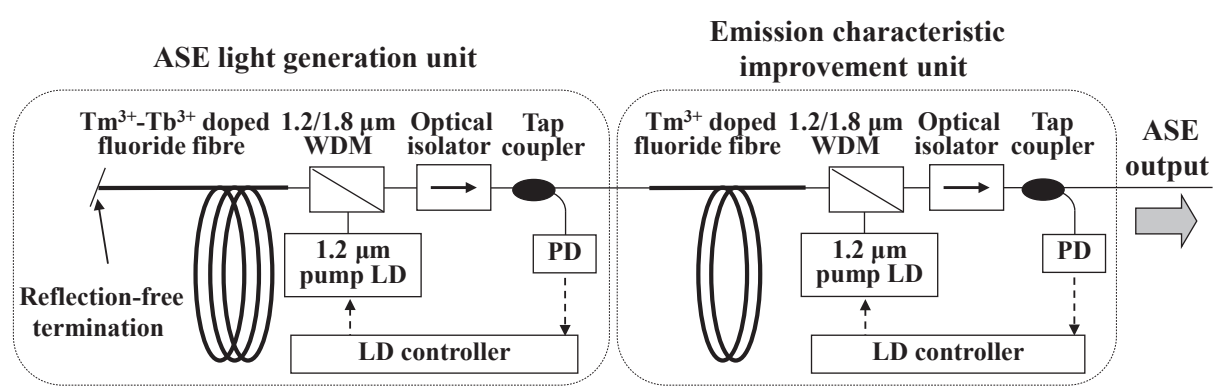

Fig. 1. $\quad 1.8 \mu \mathrm{m}$ band ASE light source configuration. 
(WDM) coupler, an optical isolator, a $1.2 \mu \mathrm{m}$ pump luminescent diode (LD), an InGaAs photodiode (PD), a tap coupler, and an LD controller, and employed a backward pump scheme for both units. Each pump LD was subject to either auto-current control (ACC) or auto-level control (ALC) by an LD controller.

A $\mathrm{Tm}^{3+}-\mathrm{Tb}^{3+}$-doped fluoride fiber was used in the generation unit. The relative refractive index difference, cutoff wavelength, $\mathrm{Tm}^{3+}$ concentration, $\mathrm{Tb}^{3+}$ concentration, and fiber length were $2.5 \%, 1.0 \mu \mathrm{m}, 2000 \mathrm{ppm}, 2000 \mathrm{ppm}$ and $20 \mathrm{~m}$, respectively. In the improvement unit, a $\mathrm{Tm}^{3+}$-doped fluoride fiber with a relative refractive index difference of $1.6 \%$, a cutoff wavelength of $1.0 \mu \mathrm{m}$, and a $\mathrm{Tm}^{3+}$ concentration of $6000 \mathrm{ppm}$ was used.

Figure 2 shows the ASE spectrum output from our ASE light source for various lengths of $\mathrm{Tm}^{3+}$-doped fibers. Each $1.2 \mu \mathrm{m}$ pump LD was under ACC, and the pump power was $90 \mathrm{~mW}$ for both units. The resolution bandwidth (RBW) of the optical spectrum analyzer (OSA) for measuring the spectrum was $1 \mathrm{~nm}$. The figure also shows the ASE spectrum from the ASE light generation unit. We found that the ASE spectrum characteristics can be improved by incorporating an emission characteristic improvement unit consisting of a $\mathrm{Tm}^{3+}$-doped fiber. We set the length of the $\mathrm{Tm}^{3+}$-doped fiber at $1 \mathrm{~m}$ to obtain an ASE spectrum with a relatively high optical power density of around $1700 \mathrm{~nm}$ for measuring organic solvents.

Figures 3 and 4 show the deviation of the ASE spectrum intensity when the ambient temperature around the light source changed from $25^{\circ} \mathrm{C}$ and the time dependence of the output total intensity with the ambient temperature change, respectively. The pump LD of the generation unit was under ACC, and the pump power was $90 \mathrm{~mW}$. The pump LD of the improvement unit was under ALC with a power setting of $12.5 \mathrm{~mW}$. We found that the ASE spectrum changes with the ambient temperature even though the total intensity is controlled by ACC. The ambient temperature of the light source must be constant to achieve a stable measurement. Therefore, we use the light source in a room maintained at a constant temperature of $25^{\circ} \mathrm{C}$ for near-IR spectroscopy. In addition, the

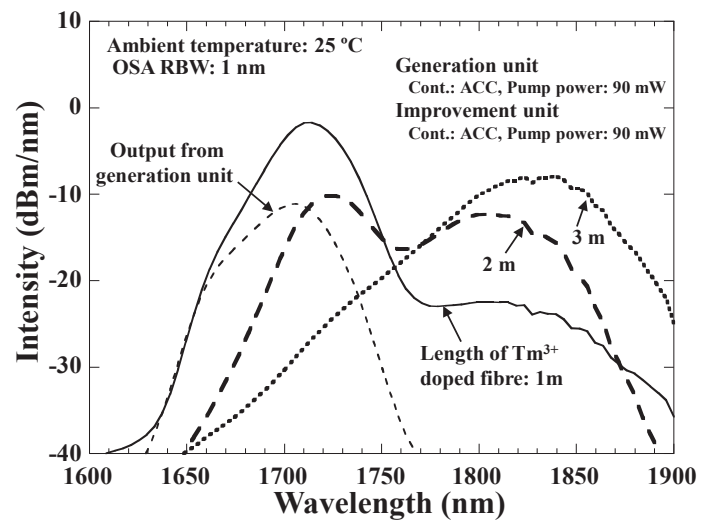

Fig. 2. ASE spectra from the ASE light generation unit and our ASE light source for various lengths of $\mathrm{Tm}^{3+}$-doped fibers. 

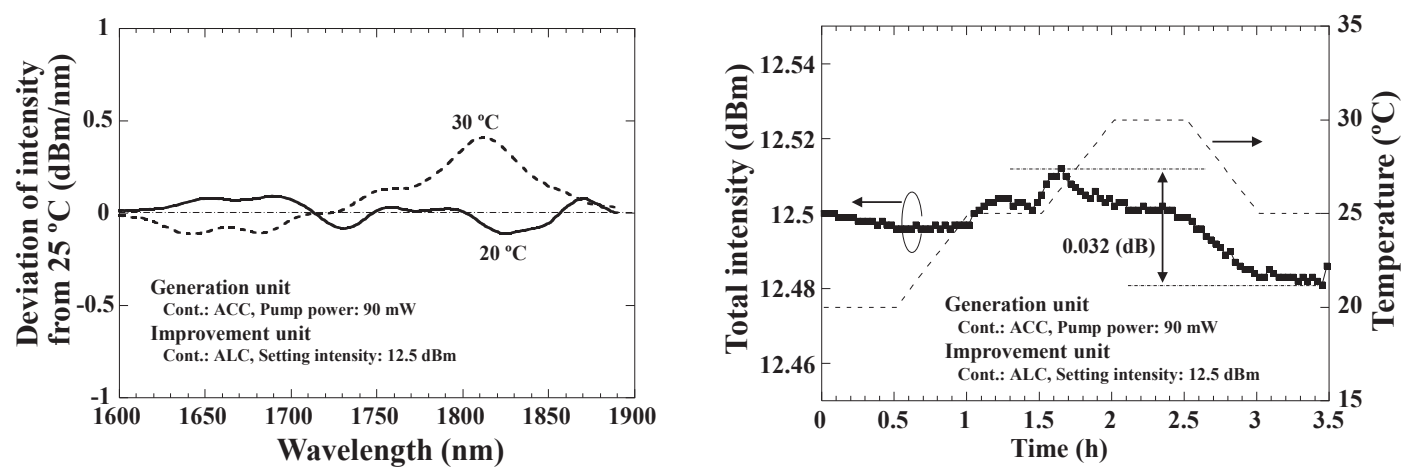

Fig. 3 (left). Deviation of the ASE spectrum intensity when the ambient temperature around the light source changes from $25^{\circ} \mathrm{C}$.

Fig. 4 (right). Time dependence of the total output intensity on the ambient temperature change.

temperature dependence of the intensity of the light source results from the changes in the level of absorption and the emission cross section of the $\mathrm{Tm}^{3+}$ and $\mathrm{Tb}^{3+}$ ions of the $\mathrm{Tm}^{3+}$-doped fiber and the $\mathrm{Tm}^{3+}-\mathrm{Tb}^{3+}$-doped fiber that are both induced by changes in temperature.

\subsection{Broadband light source in $1.8 \mu \mathrm{m}$ band}

To evaluate concentrations of organic solutes exactly, it is necessary to eliminate the influence of the absorption of water, which has absorption peaks at $\sim 1.4$ and $\sim 2 \mu \mathrm{m}$, by measuring a wavelength region wider than that of the $1.8 \mu \mathrm{m}$ band ASE light source we developed. Figure 5 shows the configuration of the two broadband light sources, types $\mathrm{A}$ and $\mathrm{B}$, that we used for our organic solute measurement. We employed a parallel configuration with the $1.8 \mu \mathrm{m}$ band ASE light source and commercially available light sources, such as a $1.65 \mu \mathrm{m}$ band SLD and/or a $1.55 \mu \mathrm{m}$ band ASE light source, and 3 $\mathrm{dB}$ couplers. The output intensities of the SLD and the $1.55 \mu \mathrm{m}$ band ASE light source were discretely controlled by ALC. The fluctuation in the total intensity was less than $0.1 \mathrm{~dB}$ for the SLD and the $1.55 \mu \mathrm{m}$ band ASE light source. The output spectra from the SLD, the $1.55 \mu \mathrm{m}$ band ASE light source, and broadband light sources, types A and B, are shown in Fig. 6. The RBW of the OSA was $1 \mathrm{~nm}$. A broadband spectrum was achieved with the parallel configuration, because the realized bandwidth for which the ASE intensity exceeded $-50 \mathrm{dBm} / \mathrm{nm}$ ranged from $\sim 1570$ to $\sim 1850 \mathrm{~nm}$ for type A, and from $\sim 1520$ to $\sim 1850 \mathrm{~nm}$ for type B.

\section{Application of Broadband Light Source to Near-IR Spectroscopy}

\subsection{Setup of near-IR spectroscopy system}

The near-IR spectroscopy system we constructed is shown in Fig. 7. The output light from the broadband light source was observed with an OSA through an optical collimation device that incorporated a silica glass cell to evaluate water solutions 
Type A

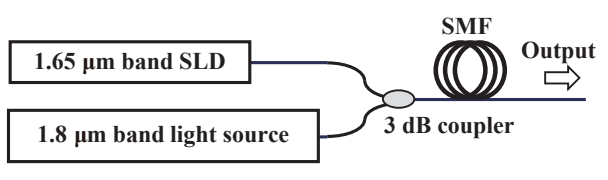

Type B

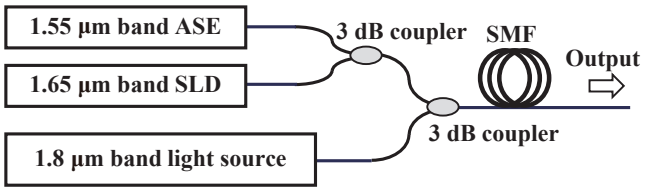

Fig. 5. Broadband light source configurations: types A and B.

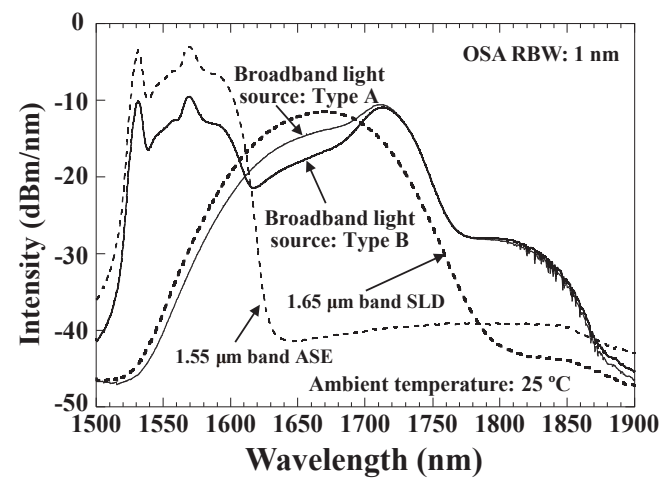

Fig. 6. Output spectra from $1.65 \mu \mathrm{m}$ band SLD, the $1.55 \mu \mathrm{m}$ band ASE light source, and broadband light sources, types A and B.

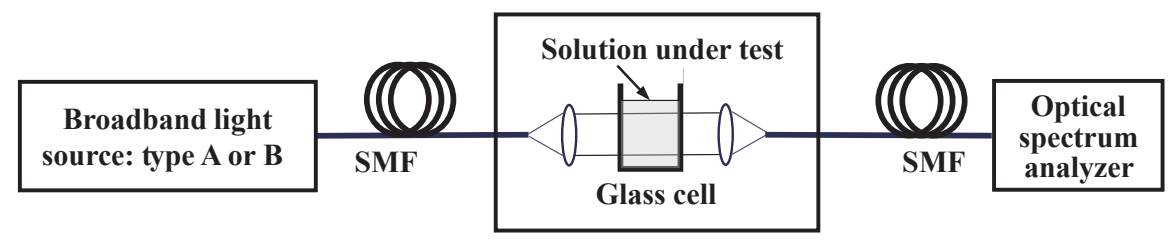

Thermostatic chamber

Fig. 7. (Color online) Near-IR spectroscopy system.

containing organic solvents. The optical length and thickness of the glass cell were 5 and $0.5 \mathrm{~mm}$, respectively. The beam diameter was $0.8 \mathrm{~mm}$. The glass cell was located in a thermostatic chamber to maintain the temperature of the solution and thus eliminate the temperature dependence of its response. Figure 8 shows the spectra observed through the collimator optical device, which contained a silica glass cell with and without ultrapure water. The RBW of the OSA was $1 \mathrm{~nm}$. The ambient temperature around the broadband light source and inside the thermostatic chamber was $25^{\circ} \mathrm{C}$. As revealed by the spectrum 


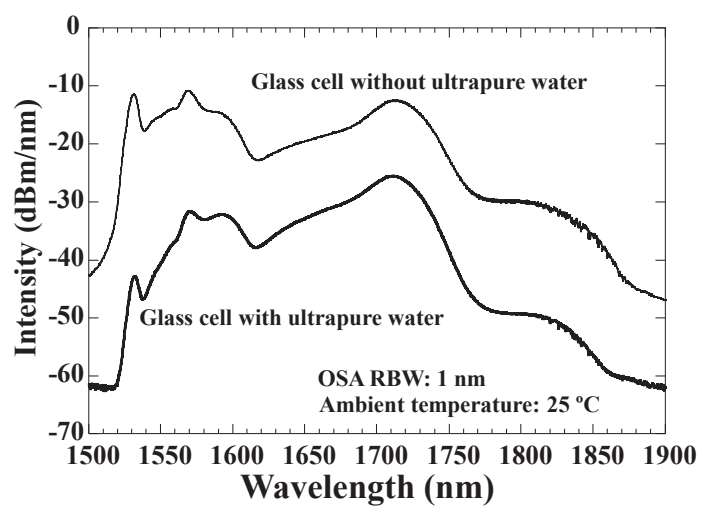

Fig. 8. Spectra observed through a collimating optical device containing a silica glass cell with and without ultrapure water.

observed through the glass cell with ultrapure water, our system can evaluate water solutions with a dynamic range of $10 \mathrm{~dB}$ in the $\sim 1520-1850 \mathrm{~nm}$ wavelength region, because the dynamic range of the OSA is $\sim 70 \mathrm{dBm} / \mathrm{nm}$.

Figures 9 and 10 respectively show the deviation of the spectral intensity when the temperature of the thermostatic chamber changes from $25{ }^{\circ} \mathrm{C}$ for a glass cell with and without ultrapure water. We found that the optical collimation device containing a silica glass without ultrapure water was less dependent on temperature, and the temperature of the organic solute being evaluated must be held constant because ultrapure water has a temperature-dependent spectrum. Therefore, we kept the temperature of the solutions of compounds at $25^{\circ} \mathrm{C}$, the same as the ambient temperature of the light source, when measuring their absorption spectrum.

\subsection{Measured results for several organic solvents}

Figure 11 shows the deviation of the absorption spectrum from those of ultrapure water, ethanol, methanol and dimethyl sulfoxide (DMSO) solutions, which were measured for various volumetric concentrations in the 0.3125 to $10 \%$ range. The wavelength region observed was from 1650 to $1800 \mathrm{~nm}$. The RBW of the OSA was $0.05 \mathrm{~nm}$. The observed absorption peak wavelengths were 1692.4, 1714.6, 1729.2, and $1759.0 \mathrm{~nm}$ for the ethanol solution; 1677.9, 1690.6, 1711.4, and $1725.8 \mathrm{~nm}$ for the methanol solution; and 1665.2, 1678.6, 1712.2, and $1725.8 \mathrm{~nm}$ for the DMSO solution. We believe the origin of each absorption peak to be molecular vibration, ${ }^{(12)}$ and that the intensity of each absorption peak increases as the concentration increases. We found that our system can measure lower volumetric concentrations of around $0.3 \%$, and has the potential to specify the identity of an organic solute from the absorption spectrum, because an organic compound has a characteristic absorption feature. 

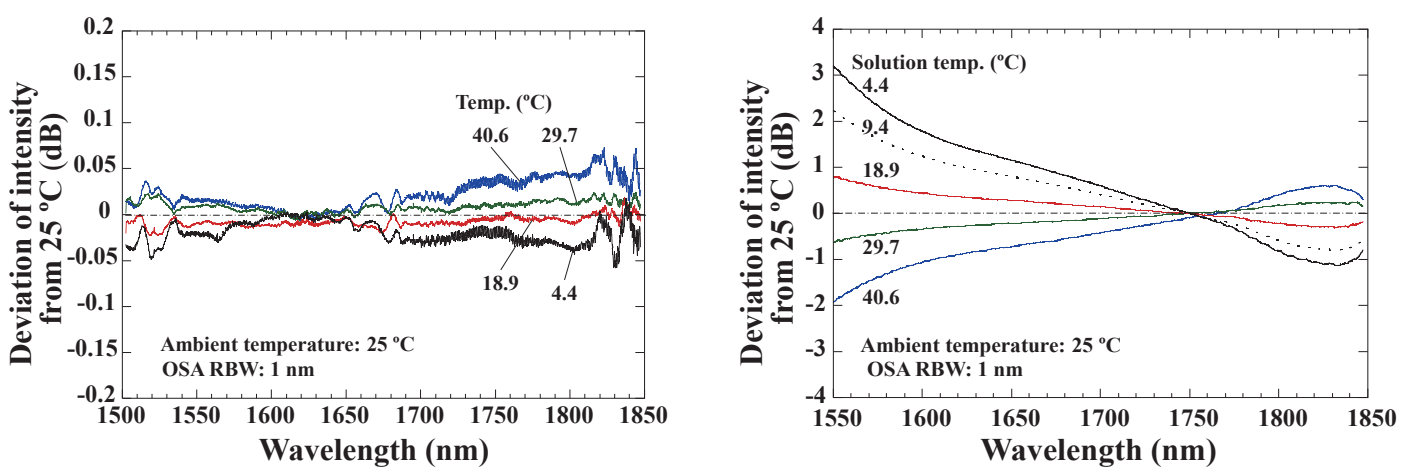

Fig. 9 (left). (Color online) Deviation of the spectral intensity when the thermostatic chamber changes from $25^{\circ} \mathrm{C}$ for a glass cell with ultrapure water.

Fig. 10 (right). (Color online) Deviation of the spectral intensity when the thermostatic chamber changes from $25^{\circ} \mathrm{C}$ for a glass cell without ultrapure water.
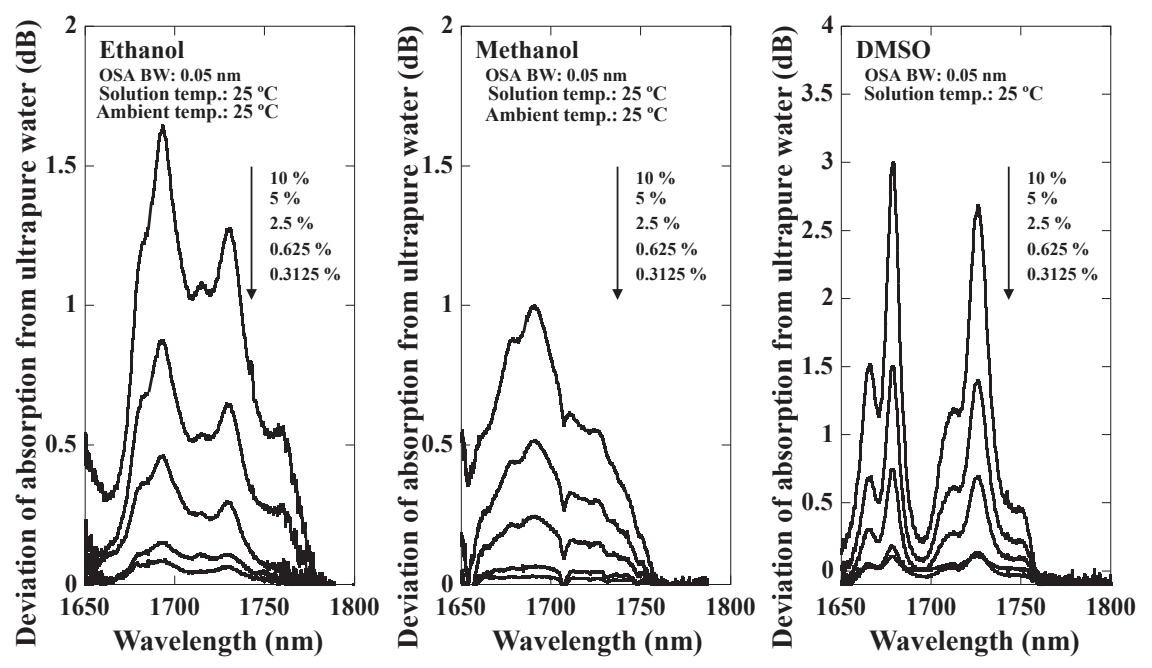

Fig. 11. Deviation of the absorption spectrum from those of ultrapure water for ethanol, methanol, and DMSO solutions.

\subsection{Results of evaluating alcohol concentration in sake}

We attempted to evaluate the alcohol concentration of sake as a potential industrial application of near-IR spectroscopy with a broadband light source. As a concentration evaluation method for the ethanol in sake, the use of a hydrometer or a mechanical oscillator densitometer, which is considered an official method of the National Tax Administration Agency of Japan for the evaluation of content, is considered. ${ }^{(16,17)}$ 
Moreover, as the other methods, there are atomic absorption spectrometry, ${ }^{(18)}$ gas chromatography, ${ }^{(19)}$ and high-performance liquid chromatography. ${ }^{(20)}$ However, it was difficult to carry out in-site measurement of a production process of sake by the abovementioned methods, and the measuring devices of atomic absorption spectrometry, gas chromatography, and high-performance liquid chromatography are very expensive. One of the evaluation methods that can be used for low-east in-site measurement is the application of a near-IR spectroscopy. Thus, we tried the following examination to discern whether the near-IR spectroscopy with the $1.8 \mu \mathrm{m}$ band can be used.

Figure 12 shows the deviation of the absorption spectrum of ethanol solution from that of ultrapure water. The wavelength region is from 1550 to $1900 \mathrm{~nm}$. The RBW of the OSA is $1 \mathrm{~nm}$. As shown in this figure, the ethanol solution has absorption peaks at 1584.0 and $1832.0 \mathrm{~nm}$, in addition to those shown in Fig. 11 at 1692.4, 1714.6, 1729.2, and $1759.3 \mathrm{~nm}$, and the intensity of each absorption peak increases as the concentration increases. The calibration curves are shown in Fig. 13. The absorption values at the maximum absorption peak wavelengths and the deviation of two absorption peak values were used for the curves in Figs. 13(a) and 13(b), respectively. Each curve has a characteristic feature proportional to the concentration. These curves have the potential to allow us to evaluate the alcohol concentration of sake.

Figure 14 shows the deviation of the absorption spectrum from that of ultrapure water for various types of sake including umeshu, unrefined sake, pure sake, and honjozoshu. In addition, the characteristic feature of unrefined sake was evaluated after centrifugation to produce a clear liquid. We confirmed that the deviations of the absorption spectrum from that of ultrapure water for each type of sake have the intrinsic absorption peaks of an ethanol solution, although there is a shift of the entire spectrum depending on the type of sake evaluated. We concluded that the shift was due to the influence of the absorption of solutes other than ethanol, and we applied the calibration curve obtained from the

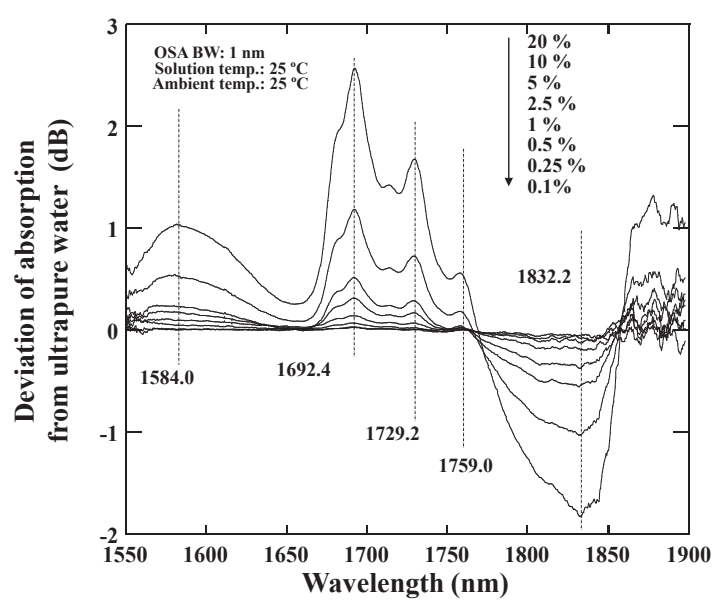

Fig. 12. Deviation of the absorption spectrum from that of ultrapure water for ethanol solution. 


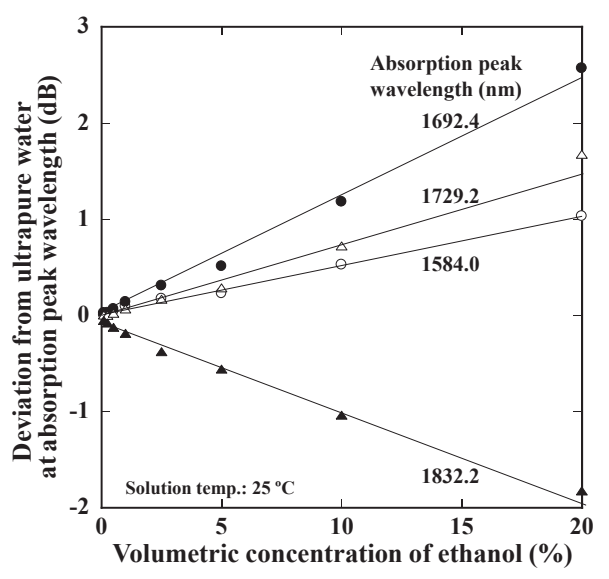

(a)

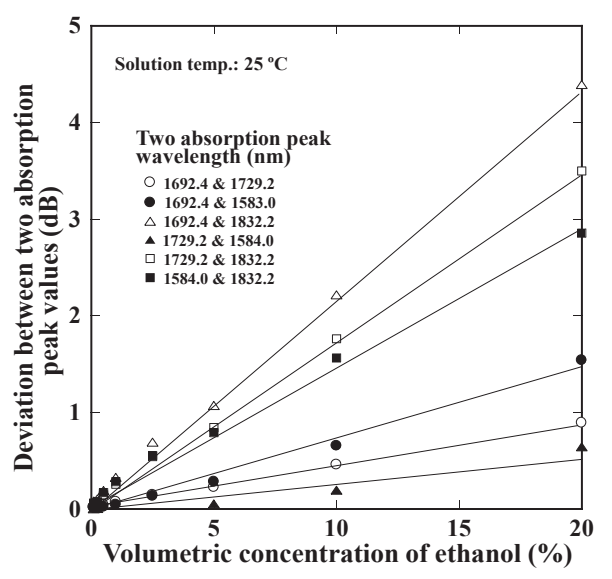

(b)

Fig. 13. (a) Calibration curves obtained from the absorption values at the maximum absorption peak wavelengths. (b) Calibration curves obtained from the deviation of two absorption peak values.

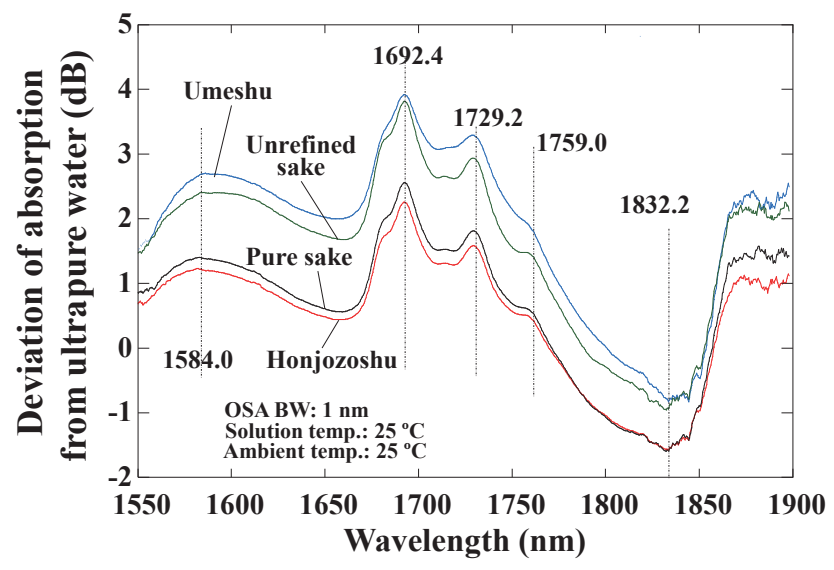

Fig. 14. (Color online) Deviation of the absorption spectrum from that of ultrapure water for various types of sake such as umeshu, unrefined sake, pure sake, and honjozoshu.

deviation of two absorption peak values to lessen the influence. Table 1 shows the deviation between two absorption values at 1692.9 and $1729.9 \mathrm{~nm}$ obtained from Fig. 14 and the concentration estimated from the deviation for each sake. This table also shows the ethanol concentration indicated on the bottle. We found that evaluation of the ethanol concentration of sake is realizable within $1.5 \%$ of the accepted value using the near-IR spectroscopy with the $1.8 \mu \mathrm{m}$ band. 
Table 1

Results of evaluation of alcohol content in sake.

\begin{tabular}{lccc}
\hline & $\begin{array}{c}\text { Deviation between two } \\
\text { absorption values at 1692.4 } \\
\text { and 1729.2 } \mathrm{nm}(\mathrm{dB})\end{array}$ & $\begin{array}{c}\text { Concentration estimated } \\
\text { from deviation of two } \\
\text { absorption values (\%) }\end{array}$ & $\begin{array}{c}\text { Labelled } \\
\text { concentration } \\
\text { value (\%) }\end{array}$ \\
\hline Umeshu & 0.6328 & 13.86 & 12.5 \\
Honjozoshu & 0.6791 & 14.87 & 15.6 \\
Pure sake & 0.7473 & 16.37 & 17.5 \\
Unrefined sake & 0.8754 & 19.17 & 18.7 \\
\hline
\end{tabular}

\section{Conclusions}

A broadband light source constructed for measuring the concentration of organic solutes was realized using a parallel configuration with a 1.8- $\mu \mathrm{m}$-band ASE light source based on a $\mathrm{Tm}^{3+}-\mathrm{Tb}^{3+}$-doped fiber and commercially available light sources, such as a 1.65- $\mu \mathrm{m}$-band SLD and a 1.55- $\mu \mathrm{m}$-band ASE light source. The realized bandwidth for which the ASE intensity exceeded $-50 \mathrm{dBm} / \mathrm{nm}$ was from $\sim 1520$ to $\sim 1850 \mathrm{~nm}$ for the broadband light source with a 1.8- $\mu \mathrm{m}$-band ASE light source, a 1.65- $\mu \mathrm{m}-\mathrm{band}$ SLD, and a 1.55- $\mu \mathrm{m}$-band ASE light source.

A near-IR spectroscopy system employing the developed broadband light source was constructed. We confirmed the effectiveness of our system for the evaluation of the concentration of organic solutes, because the system can measure low volumetric concentrations of around $0.3 \%$ for ethanol, methanol and dimethyl sulfoxide solutions, and has the potential to allow identification of the organic solute by observing the absorption spectrum, because each organic compound has a characteristic absorption feature.

Furthermore, the system was used to evaluate the alcohol concentration of sake as a possible industrial application. We found that the ethanol concentration of sake can be evaluated with an accuracy within $1.5 \%$ of the accepted value using the near-IR spectroscopy with the $1.8 \mu \mathrm{m}$ band.

A near-IR spectroscopy system employing our broadband light source is attractive for use in scientific experiments such as those involving near-IR spectroscopy.

\section{References}

1 D. C. Hanna, R. M. Percival, R. G. Smart and A. C. Tropper: Opt. Commun. 75 (1990) 283.

2 T. Yamamoto, Y. Miyajima, T. Komukai and T. Sugawa: Electron. Lett. 29 (1993) 986.

3 W. A. Clarkson, N. P. Barnes, P. W. Turner, J. Nilsson and D. C. Hanna: Opt. Lett. 27 (2002) 1989.

4 D. Y. Shen, J. K. Sahu and W. A. Clarkson: Opt. Express 14 (2006) 6084.

5 Y. Tang, F. Li and J. Xu: IEEE Photon. Technol. Lett. 23 (2011) 893.

6 S. Ishida, N. Nishizawa, T. Ohta and K. Itoh: Appl. Phys. Express 4 (2011) 052501.

7 Y. Tang, C. Huang, S. Wang, H. Li and J. Xu: Opt. Express 20 (2012) 17539. 
8 A. B. Rulkov, A. A. Ferin, J. C. Travers, S. V. Popov and J. R. Taylor: Opt. Commun. 281 (2008) 154.

9 M. Yamada, S. Aozasa and H. Ono: Electron. Lett. 48 (2012) 1489.

10 M. Yamada, K. Senda, T. Tanaka, Y. Maeda, S. Aozasa, H. Ono, K. Ota, O. Koyama and J. Ono: Electron. Lett. 49 (2013) 1287.

11 M. Ebrahim-Zadeh and I. T. Sorokina: Mid-Infrared Coherent Sources and Applications (NATO Science for Peace and Security Series, Springer, New York, 2008) p. 465.

12 Y. Ozaki and S. Kawata: Near-Infrared Spectroscopy (Scientific Societies Press, Tokyo, 1996) (in Japanese).

13 A. D. Ellis: Proc. IEEE Summer Topical Meeting SDM Optical Systems Networks, 2012 (2012) p. 169 .

14 D. J. Richardson: Proc. Optical Fiber Communication Conference (OFC) 2013.

15 Y. Maeda, M. Yamada, T. Endo, K. Ohta, T. Tanaka, M. Ono, K. Senda, J. Ono and O. Koyama: Proc. OptoElectronics and Communications Conference (OECC) 2014.

16 Official Methods of the National Tax Administration Agency of Japan for the Evaluation of Content (in Japanese).

17 JIS Z 8804, Methods of Measuring Density and Specific Gravity of Liquid (in Japanese).

18 JIS K 0121, General Rules for Atomic Absorption Spectrometry (in Japanese).

19 JIS K 0123, General Rules for Gas Chromatography / Mass Spectrometry (in Japanese).

20 JIS K 0124, General Rules for High-Performance Liquid Chromatography (in Japanese). 